\title{
Literatura e Ciência da Informação
}

\author{
Solange Puntel Mostafa \\ Doutora em Educação pela Pontifícia Universidade Católica de São Paulo \\ Professora do curso de Ciências da Informação e da Documentação da FFCLRP/USP \\ E-mail: $\underline{\text { smostafa@ } @ f f c l r p . u s p . b r}$
}

ALMEIDA, M. A. Ciência da informação e literatura: práticas e reflexões. Campinas: Átomo e Alínea, 2012.

O livro organizado por Marco Antônio de Almeida traz curiosa intercessão entre Ciência da Informação e Literatura; o livro está sendo lançado, em janeiro de 2012, pela editora Átomo e Alínea de Campinas, SP, na forma de e-book (a obtenção de exemplares impressos pode ser realizada no contato com a editora). O livro compreende refinados seis capítulos escritos por professores de Ciência da Informação da USP, campus de Ribeirão Preto, SP. São eles: A Literatura Infantil em Diálogo com a Biblioteca Escolar (Cláudio Marcondes de Castro Filho); A paixão inscrita no discurso da exposição de/sobre Clarice Lispector (Lucília Maria Sousa Romão); Tecendo tramas literárias para uma narrativa da memória (Giulia Crippa); Literatura, informação, conhecimento e ciência: considerações a partir da literatura policial (Marco Antônio de Almeida) e O caso do Cientista da Informação que estudava Filosofia e adorava Literatura (Denise Viuniski da Nova Cruz e Solange Puntel Mostafa).

Deleuze e Guattari dizem que certos romancistas fazem o romance do espinosismo. Querendo dizer que alguns romances ou romancistas dão conta de nos apresentar o mundo em movimento de corpos. E que tudo nessa vida não passa de encontros, oportunidades. A ciência da informação já é passível de uma historiografia pois vem interferindo no mundo da ciência e tecnologia há quarenta anos, desde sua emergência na segunda metade do século XX. Entretanto, as instituições informacionais, como bibliotecas, arquivos e museus são tão antigas quanto as civilizações. Pensadas em ambientes de formação profissional como os cursos universitários, essas instituições e o saber sobre elas provocam transformações referenciais, no tempo e no espaço. O saber universitário é por isso dito científico, pois é sistematizado e referencial. Mas os planos entre ciência, arte e filosofia deslizam uns sobre os outros, provocando ressonância entre uns e outros. Este livro faz deslizar Literatura e Ciência da Informação. Deslizar entre os planos para os autores deste livro, significa mexer nos 
conceitos científicos da ciência da informação, mas como temos dito, o processo assemelha-se mais a reverberações não intencionais. É como se a literatura capturasse em suas malhas, os autores deste livro, fazendo-os devir cientistas da informação literários. Arte, Ciência e Filosofia têm em comum a força criadora e a capacidade de realizar movimentos no pensamento. Movimentos que fazem a Literatura e a da Ciência da Informação ressoarem uma na outra.

Vimos surgir, pela primeira vez, na Ciência da informação, a expressão A literatura $e$ a Ciência da informação no texto de Sidney Barbosa (2009). Concordamos com o autor em distinguir a Literatura de outros discursos como os filosóficos, científicos, os religiosos ou os discursos históricos. Aceitamos até certo ponto que a produção literária, materializada em um conto, um romance ou uma peça teatral não está desvinculada do contexto histórico e social que lhe deu origem; entretanto, entendemos que é a ultrapassagem desse momento históricosocial vivido pelo romancista que faz dele um vidente, a nos arrastar para mundos impensáveis e atemporais. Este é o papel da literatura no mundo: criar outros mundos e nos fazer devir outros, diferentes de nós mesmos.

Veja-se por exemplo, a obra dos dois romancistas brasileiros aqui tratados: Guimarães Rosa e Clarice Lispector; ambos nos fazendo virar onça e barata, num devir-animal impensáverl para nossa humanidade histórica e cultural. É que ambos saem do plano do vivido e de suas histórias pessoais, construindo um outro plano mágico de pensamento, fora da história e do tempo, para onde nos levam a viver perigos no limite de nossa deshumanidade.

Outros romancistas apresentados neste livro nos levam a refletir sobre os caminhos da memória; é o caso dos escritores laureados com o prêmios Nobel de literatura apresentados no capítulo Tecendo tramas literárias para uma narrativa da memória, capítulo assinado por Giulia Crippa. O leitor entrará em contato com os escritos de Jorge Luis Borges, Umberto Eco, Salman Rushdie, Orhan Pamuk, Emile Zola, Luigi Pirandello e Heinrich Boll; nesses percursos literários, a obra de arte se apresenta também como uma problemática da memória individual e coletiva.

$\mathrm{Na}$ companhia destes romancistas o leitor visitará outros mundos próximos dos cientistas da informação ou dos museólogos, bibliotecários e arquivistas. Estes romancistas sabem que os leitores também são seres inventivos e que por isso, podem acompanhá-los em algumas dessas viagens. Por isso, nos escrevem; alguns de seus romances ou contos são 
cartas-convite: "estou procurando, estou procurando; estou tentando entender. Tentando dar a alguém o que vivi..." Assim começa a paixão de Clarice trazida pela professora Lucilia Romão, no capítulo intitulado A paixão inscrita no discurso da exposição de/sobre Clarice Lispector. Em outros momentos da obra de Clarice Lispector há ponderações nessa entrega: "que mal porém, tem, em eu me afastar da lógica? Estou lidando com a matéria prima. Estou atrás do que fica atrás do pensamento" (p. 13 Agua viva).

Encanta-nos esse mundo para nós desconhecido: que lugar é esse, atrás da linguagem e do pensamento? Um lugar seco, diz ela e impessoal. "O "it": eu tenho o impessoal dentro de mim" (p. 30 idem). A transcendencia para Clarice é o "it", o impessoal e é de lá que ela escreve. De um entre-lugar, um não-lugar, puro fluxo de percepções que faz lembrar a coleção sem álbum de David Hume quando teoriza sobre as percepções como um fluxo ininterrupto, anteriores ao nascimento do sujeito ou objeto. Clarice adverte: "Quem for capaz de parar de raciocinar ... que me acompanhe" ) p. 33 idem.

Nessa impessoalidade parece que a autora atinge o estado de graça puramente intuitivo de que fala Espinosa no terceiro gênero de conhecimento. Extasiada com essa graça, Clarice vai ao dicionário procurar o significado da palavra beatitude, repudiando qualquer estado místico ou religioso. Concluindo que liberdade é esse estado de anonimato no mundo, quando o verdadeiro pensamento se pensa a si mesmo, tão livre que "ao próprio pensador esse pensamento parece sem autor". (idem p. 89). O que te escrevo, diz ela, é um "isto"; não vai parar: continua. (idem p. 95).

Pois bem, leitor, o que os professores-autores deste livro te escrevem é também um "it" e não vai parar. Misto de arte e ciência da informação, este it é um convite para uma conversa: à pergunta da professora Lucília Romão, sobre outras formas de ler uma exposição, responderíamos que a Ciência da Informação vem inovando formas próprias justamente por entender que a palavra erra por terras estrangeiras. Os tesauros e a classificação por facetas são algumas invenções propostas pela Ciência da Informação para solucionar a errancia da linguagem por terras estrangeiras. A língua dentro da língua de Rosa é uma criação artística; a língua dentro da língua de um tesauro temático, tal como é o processo documentário proposto pela Ciência da Informação é uma criação científica. Pois a linguagem documentária é uma linguagem artificial com elementos da linguagem natural. Analistas de discurso e cientistas da informação têm, por isso, muito a aprender uns com os outros. A noção de discurso é relevante em alguns casos enquanto em outras, uma linguagem documentária menor pode 
estar enunciando novos caminhos para a Ciência da Informação: é o que demonstram Nova Cruz e Mostafa no capítulo intitulado $O$ caso do Cientista da Informação que estudava Filosofia e adorava Literatura. Uma nova organização da informação baseada em afetos, a categoria espinosista por excelência é proposta por este cientista da informação que adorava a os escritos de Guimarães Rosa. Mas atenção: Clarice Lispector também é leitora de Espinosa, e por isso traz vestígios desta inspiração espinosista na paixão segundo $G$. $H$. : trata-se do encontro de corpos; corpos que se afetam e só podem se afetar porque são móveis e movediços, na expressão de Romão. O movimento de corpos é também o movimento de idéias e de sensações. O corpo de Clarice, o corpo da barata, o corpo da linguagem, o corpo de todos nós, numa ultrapassagem de nossa própria humanidade em direção ao impessoal, ao pré-subjetivo e ao virtual do tempo. Ao aproximar os planos da ciência e da arte literária, os autores não abandonam os catálogos e suas linguagens documentárias, mas os re-inventam em novas forças, novas estórias, e quiça inspiram o surgimento de uma nova ciência da informação. Deixei por último o texto do organizador do livro: trata-se de uma sociologia do romance policial, em que Marco Antonio de Almeida contextualiza o romance policial no movimento das idéias sociológicas, não faltando citações a Durkheim ou a Augusto Comte, sociólogos também em busca de rigor lógico para os fatos policialescos da sociedade. Mas Almeida cruza a nova sociologia e/ou antropologia de Bruno Latour para destacar as relações entre os fatos (não os fatos mesmos) como algo de valor para a Ciência da Informação, uma vez que a Informação é um nó em uma rede de relações. E no romance policial o nó é referencial, lógico, científico e deste mundo. Em Almeida, a literatura cruza com a ciência a partir da literatura policial e, por isso torna-se mais social e mais sociológica.

Esse livro interessa a romancistas e literatos, aos psicólogos, pedagogos, bibliotecários, pessoal de letras, arquivistas, museólogos e demais profissionais que lidam com informação e subjetividade e pode estar sendo explorado tanto em nível de graduação quanto em nível de pós-graduação. O livro é a um só tempo livro de cabeceira e de sala de aula.

\section{Referência}

BARBOSA, S. A literatura e a ciência da informação. In: CASTRO SILVA; BARROS, M. H. Ciência da Informação; múltiplos diálogos. Marília: Oficina Universitária Unesp, 2009. p. $77-78$

Resenha enviada em: 07 out. 2011.

InCID: R. Ci. Inf. e Doc., Ribeirão Preto, v. 2, n. 2, p. 213-216, jul./dez. 2011. 